\title{
Impact of environmental triggers on students' behavior to use ride- sharing services: the moderating role of perceived risk
}

\author{
Syed Ali Raza ${ }^{1}$ Komal Akram Khan ${ }^{1}\left[\right.$ ] Javeria Salam ${ }^{1}$ \\ Accepted: 13 October 2021 \\ (c) The Author(s), under exclusive licence to Springer Science+Business Media, LLC, part of Springer Nature 2021
}

\begin{abstract}
Ride-sharing services are a sustainable form of the transportation system that needs to be popularized among students by examining the crucial factors that determine the students' behavior to use the innovative service. Therefore, this paper attempts to explore students' behavior regarding the use of ride-sharing services by extending the "Technology Acceptance Model." The expanded model includes the current TAM structures and integrates contextual stimuli that may or may not affect the ride-sharing service's behavior. Moreover, the study focuses on determining the moderating role of perceived risk between the proposed relationships. The paper uses PLS-SEM to analyze the research model and determine the results of the hypotheses. The findings of this research are useful for ride-sharing service providers and policymakers who can promote the services among students by reducing the perceived risks and promoting the environmental benefits of ride-sharing. Furthermore, the limitations of this paper pose future research directions.
\end{abstract}

Keywords Ride-sharing services · Environment · Students' behavior · And smart-PLS

\section{Introduction}

A modern economic model emerges where organizations and individuals work together, distribute, exchange, and reuse surplus products or services across online platforms (Hamari et al., 2016; Wang et al., 2020). According to Heinrichs (2013), a sharing economy makes full use of market intelligence by fostering an eco-friendly, sustainable, and collaborative society. An example of this is the introduction of "Ride-Sharing Services." One of the earliest and most common forms of the sharing economy is ride-sharing (Zhu et al., 2017) that refers to an evolving transportation mode in which people with similar or partially overlapping travel routes and times agree to share their journey in an effort to reduce travel expenses (Lokhandwala \& Cai, 2018) and the possible environmental degradation caused by traveling.

Syed Ali Raza

syed_aliraza@hotmail.com

Komal Akram Khan

komalkhan0331@hotmail.com

Javeria Salam

javeriasalamazizi@gmail.com

1 Department of Business Administration, IQRA University, Karachi 75300, Pakistan
According to Wang et al. (2020), the reason for the ridesharing model's rapid development in the past decade is due to the rise in mobile technology that established the ground for using internet-based applications and the Global Positioning System (GPS). Further, cloud computing technologies enable ride-sharing service providers to make transportation much more convenient and flexible through collaboration consumption (Dong et al., 2018; Yin et al., 2018). Internet-based ride-sharing services provide numerous benefits; hence, it has become increasingly attractive and has given rise to its popularity among consumers (Schor, 2016). Its benefits relate mainly to the fair distribution of automotive resources, reduced energy consumption, and attainment of shared profits by all parties involved i.e., drivers, commuters, and service providers (Dong et al., 2018; Hamari et al., 2016; Wang et al., 2019). These services work through effective utilization of free seats, as drivers are to drive from their starting point to the end (Frenken \& Schor, 2019), thus reducing time and costs by taking several passengers to their destination in one go (Agatz et al., 2012; Liu et al., 2017). Ride-sharing services play a major role in environmental protection, as free seats are utilized, the number of vehicles out on the road for personal trips significantly decrease, which ultimately reduces traffic congestion, mitigates consumption of fuel, and cuts greenhouse gas 
emissions (Agatz et al., 2012; Dong et al., 2018; Teubner $\&$ Flath, 2015). Ride-sharing also carries a few benefits for society. It enables passengers having different backgrounds to meet while traveling to their destination, improving their interpersonal skills, knowledge, and building trust among people, as positive social interaction is promoted (Hwang \& Griffiths, 2017). Despite all the benefits of ride-sharing services, people are still reluctant to adopt because of the risk. Many consumers continue to be uninterested in this new and ecological mode of transportation, and others actively refuse it because of potential risks. Cheng (2016) and Zhu et al. (2017) stated that GPS technology and mobile Internet based services are considered risky because of online transaction procedure and offline experience as well. Similarly, Ridesharing, a novel "online-to-offline (O2O)" service is highly suspicious among people because of the online and offline threats. Hong et al. (2017) discussed some risks with respect to online transportation, i.e., problems relating to personal security, privacy, property safety, expected performance, and compensation for accidents. Hence, the risk is the major obstacle in the way of new technologies.

In recent decades, a huge range of policies through local and regional governments have been actively proclaimed by many developed countries, including Britain, the USA, Canada, and Germany, to foster ride-sharing, which aims to reduce travel congestion and allow individuals to build environmentally friendly travel habits (Wang et al., 2020). Similarly, several researches are available that study ridesharing services in developed countries. For instance, recent research analyzes the consumers' intention to use ride-sharing services in the Covid-19 pandemic. The scholars targeted Uber services and concluded that the consumers of Egypt are more likely to depict positive behavior towards the usage of ride-sharing services (Rasheed et al., 2021). Furthermore, Wang et al. (2020) extend TAM to evaluate customers' intentions to adopt ride-sharing services. As per the results, the PEU has no noticeable influence on the intention to adopt ride-sharing services. However, personal innovativeness is associated with higher PU and PEU. In contrast, a negative association is found with PR. Another research by Wang et al. (2019) claimed that perceived value fosters willingness of consumers to participate in ride-sharing, but perceived risk is adversely linked with consumers' willingness.

Ride-sharing services are an emerging concept in developing countries and have been spreading rapidly (Yuana et al., 2019). However, to the best of the authors' knowledge, few studies on ride-sharing have been done in developing countries (Yuana et al., 2019; Shah et al., 2020; Akbari et al., 2020; Paundra et al., 2020). Though, in a country like Pakistan, this study area is still untouched. After reviewing the benefits of ride-sharing services, the scholars believe that it is essential to explore the behavior of Pakistani people toward the use of ride-sharing services. The motivation for conducting the present research in Pakistan includes the following: (i) Pakistani consumers face issues in traditional taxis, such as the unfair price, insecurity, and nonexistence of compliance with official rules and regulations of driving and safety. Hence, people welcome online ride-sharing services because they consider them easy to use, timely approachable, and reasonable fare charging (Abd Elmeguid et al., 2018). Therefore, the market and sector have immense potential and opportunity in Pakistan. So, it is essential to investigate the factors of ride-sharing behavior by focusing the people of Pakistan. (ii) Some prior studies claimed that people use ride-sharing services to reduce travel expenses, pollution, and traffic (Wang et al., 2019; Wang et al., 2020). Feeney (2015) informed that the government of China has started to accept the concept of ride-sharing services and has been actively emphasizing the environmental benefits of using the innovative service. Similarly, in Pakistan, the concept of a sustainable environment has gained massive attention from scholars and practitioners. Many researches have been conducted in this regard and reveal that environmental knowledge, awareness, and concern among the people of Pakistan boost green behavior (Ahmed et al., 2020; Faize \& Akhtar, 2020; Rustam et al., 2020). Hence, a question arises, whether environmental triggers (environmental knowledge, environmental awareness, and environmental concern) foster consumers' behavior to use ride-sharing services? Additionally, the literature does not have empirical studies with respect to environmental triggers and ride-sharing services. Thus, it is critical to address the gap in Pakistan's context as transportation-related difficulties in Karachi have grown significantly over the last few decades. Further, traffic congestion causes air and noise pollution, resulting in health issues, higher accident rates, and damage to the environment (Farooqi et al., 2020; Munir et al., 2021). Therefore, this aspect will be a new addition to the literature of green environment and ride-sharing services.

The current research makes four significant contributions. First, it studies the students' BI to use ride-sharing services in the context of Karachi, Pakistan, as it is a metropolitan city and holds a huge market for this sector. So, it will provide an insight to the online transportation industry and the government regarding ride-sharing services so that they can collectively promote it among the students of higher education that might ultimately help in resolving their transportation issues. Second, it includes the environmental triggers (concern, knowledge, and awareness) in the research framework to analyze their influence on students' BI. Thus, by promoting ride-sharing services, the environment can be protected from further degradation. Third, the moderating role of a multi-dimensional framework of the consumers' perceived risk has been added to examine how the risk associated with ride-sharing services affects the proposed association. In this paper, perceived risk is the focus because of 
the fact that ride-sharing is a new developing technology; the risks linked with its use are generally a source of concern for non-user. Therefore, it is necessary to explore the moderating role of PR in the case of non-users' behavioral intentions. Non-users must be studied since the transition from non-users to users is a lengthy process in which wellplanned explanation, guidance, and help from providers and authorities is crucial to attract consumers who have never experienced or used ride-sharing earlier (Liao et al., 2015). The academic community has paid insufficient attention to scholarly investigation on the acceptability of this form of transportation technology among consumers, particularly from non-users' perspective. Recent research by Wang et al. (2020) targeted the non-users, but the authors solely focus on risk perception and value perception factors that might lead to a willingness to use ride-sharing services. So, the fourth contribution is all about focusing on non-users' behavior so that researchers can fill the void and put forward relevant regulatory strategies.

The remaining paper is organized as follow. The second section presents theoretical background with relevant discussion of hypotheses. Third section includes the data collection methods, a sample of this study, and research instruments. Fourth section presents the data analysis with the discussion of the results. Then, fifth section conclude the paper along with policy implication.

\section{Literature Review}

\section{Theoretical Background}

This research uses the "Technology Acceptance Model (TAM)". TAM was originally introduced by Davis et al. (1989); the constructs of TAM include "Perceived Ease of Use (PEU)" and "Usefulness (PU)," as they are considered critical factors for analyzing consumers' behavior of using innovative technology (Davis, 1989).

TAM has been employed as a theoretical foundation in this study because it is regarded as a common and effective model for addressing the consumer acceptance paradigm in relation to a new technology (Hubert et al., 2017; Prieto et al., 2014; Cheung \& Vogel, 2013; Ha \& Stoel, 2009; Davis, 1989). In addition, TAM includes two crucial factors, i.e., PEU and PU, that explain the success of new technology adoption more accurately because the first thing consumers consider is the usefulness and easiness of that technology (Davis, 1989). However, other technology acceptance models talk about advanced aspects that consumers might consider after learning about technology's usefulness and convenience. Much preceding research has taken TAM to study and evaluate the usability and feasibility of these shared services by users. Such as, Chen and Lu (2016) employed the green TAM to investigate consumers' intentions to adopt "public bike-sharing services" from the aspect of environmental protection. The authors discovered that the green TAM is a useful paradigm for explaining the elements that influence consumers to adopt sustainable transportation. Another study investigated the intention of "Swedish Generation Y" users to use Uber's ride-sharing services by employing two theories i.e., "theory of planned behavior" and "technology acceptance model" (Fleischer \& Wahlin, 2016).

The extended framework developed by the authors incorporates environmental triggers, which include Environmental Concern (EC), Knowledge (EK), and Awareness (EA), to evaluate their impact on the behavior of students in terms of adopting the use of ride-sharing services. Furthermore, the model incorporates PR as a moderating variable to interpret its relationship among variables.

\section{Hypotheses Development}

\section{Perceived Ease of Use and Students' Behavior}

Studies in the area of Technology acceptance demonstrated that several scholars researched the effect of Perceived Ease of Use (PEU) on BI and found that it had a positive and significant relationship (Davis, 1989; Davis et al., 1989). PEU is a metric that builds users' understanding of the degree of complexity of the technology, and the lower the complexity of the technology, the greater the chances of users using the technology (Legris et al., 2003; Venkatesh \& Davis, 2000). As this paper focuses on the acceptance of ride-sharing services among students, PEU is the degree to which students think the technology is convenient and free of effort. Nikou and Economides (2017), Chin and Todd (1995), and Mallat et al. (2009) found a positive link between users perceiving the technology as easy to use and their BI. In contrast, Wang et al. (2020) revealed in their study that consumer's PEU regarding the use of ride-sharing services in the context of China and found that it did not influence their BI. Thus, our research tests the following hypothesis in line with the literature:

\section{"H1: PEU has a positive relationship with BI"}

\section{Perceived Usefulness and Students' Behavior}

Perceived Usefulness (PU) is also a popular construct measured by several scholars in the technology acceptance literature as a significant determinant of BI (Davis, 1989; Davis et al., 1989). Legris et al. (2003) and Venkatesh and Davis (2000) define PU as the extent to which a technology is deemed to be helpful and useful for performing different tasks. According to Park et al. (2014), consumers are 
more likely to experience innovative technology when they decide it is useful and beneficial to their aim. In the context of ride-sharing services, $\mathrm{PU}$ is the extent to which a consumer believes using the service will lower expenditure and offer a better commuting experience. Earlier studies have examined the influence of PU on the BI of technology use and found that the constructs are positively linked (Chin \& Todd, 1995; Mallat et al., 2009; Cheng \& Huang, 2013; Park et al., 2014; Tan et al., 2014; Mac Callum \& Jeffrey, 2014). Research conducted in ride-sharing services in China indicated that consumers' PU of ride-sharing services influenced their BI (Wang et al., 2020). In line with the review of the literature, our research tests the following hypothesis:

"H2: PU has a positive relationship with BI".

\section{Environmental Concern and Students' Behavior}

Environmental Concern (EC) is explained by Schwartz (1977) through his Norm Activation Theory, which defines it as an awareness of the implications that give rise to a sense of responsibility when carrying out any action (Fujii, 2006). As Fransson \& Gärling, 1999 indicated that measuring EC to understand environmentally friendly behavior is essential; it makes it critical to evaluate students' concern regarding the environment in the context of ride-sharing services to analyze its impact on their BI. Pagiaslis and Krontalis (2014) revealed that in the literature, EC is widespread as it is considered an important factor for influencing consumer behaviors. Prior studies report that EC of consumers is positively associated with consumers' willingness to pay for renewable energy (Bang et al., 2000), making eco-friendly purchase decisions (Kalafatis et al., 1999; Schwepker \& Cornwell, 1991), and their usage intentions (Alwitt \& Berger, 1993). Consequently, the authors of this study attempt to assess the student's EC for analyzing their BI to use ride-sharing services. Henceforth, in line with the review of the literature, our research tests the following hypothesis:

"H3: EC has a positive relationship with BI".

\section{Environmental Knowledge and Students' Behavior}

Environmental Knowledge (EK) is defined by Mostafa (2007) as the degree of what consumers know about the environmental situation and how they appreciate the people involved in the holistic system view and joint responsibilities required for sustainable development. According to Pagiaslis and Krontalis (2014), EK can either be objective, which is the knowledge of environmental problems and their causes, or the perceived subjective knowledge about ecofriendly actions. Consumer behavior literature shows that consumer EK is positively linked to their green purchasing behavior (Mostafa, 2007) and that EK has a positive impact on consumers' green purchasing behavior (Tanner et al., 2004; Tanner \& Wölfing Kast, 2003; Tilikidou \& Delistavrou, 2006). However, some researchers have found that subjective EK has a greater impact on consumer purchasing behavior (Ellen, 1994). The construct of EK in the context of ride-sharing services is consumers' knowledge regarding the reduced carbon footprint of using the service. Bang et al. (2000) revealed in their study in the area of renewable energy that consumer's knowledge regarding sustainable energy sources boosts their intention to pay for those services. Thus, the authors assume the positive link of EK with student's BI to use ride-sharing services and propose the following hypothesis:

\section{"H4: EK has a positive relationship with BI".}

\section{Environmental Awareness and Students' Behavior}

Environmental Awareness (EA) is defined by Hopwood et al. (2005) as a comprehensive construct that includes consumer's perception, cognition, and sensibilities regarding the prevailing environmental issues, and their attitude towards solving these issues and working towards the improvement of the quality of the environment for a sustainable future. According to Schuitema et al. (2013), EA is concerned with consumers' awareness regarding the influence of their actions on the environment, which invokes making environmentally friendly decisions (Daziano \& Bolduc, 2013; Wang et al., 2016). Several scholars have investigated the construct and revealed that consumers who have a higher level of EA are more likely to engage in eco-friendly behavior (Bansal, 2011; Chen \& Hung, 2016; Kahn, 2007). A study explored the BI of the bike-sharing system and revealed that it was positively influenced by consumer's EA (Fishman et al., 2013). Hence, in line with the review of the literature, the authors of this paper predict greater EA will lead to an increase in student's BI of ride-sharing services and thus propose the following hypothesis:

"H5: EA has a positive relationship with BI".

\section{Moderating Role of Perceived Risk}

Perceived risk (PR) is defined by Bauer (1960) as the negative consequences that can occur when a consumer purchases a new product or service. It is considered as one of the important and well-accepted concepts in the area of consumer behavior. Some scholars argued that TAM only considers the possible gains of using new technology but does not consider the possible losses or resistance factors 
(Park et al., 2014; Cheng \& Huang, 2013). Hence, some scholars identify PR as a crucial obstacle for consumers' technology acceptance (Kim et al., 2008; Luo et al., 2010) as it considerably lowers consumers' positive perceptions of new technology (Liu \& Wei, 2003; Martins et al., 2014). Also, it makes them less interested in using that technology (Wang et al., 2018; Martins et al., 2014). Thus, researchers have developed a multi-dimensional approach to explore how PR impacts consumer's acceptance level of technology (Luo et al., 2010; Martins et al., 2014; Park \& Tussyadiah, 2017). Researchers have noted that consumers are usually worried about their privacy (Cheng, 2016; Dillahunt \& Malone, 2015; Zhu et al., 2017; Zhu et al., 2018), security (Lee et al., 2017; Yang et al., 2015), performance (Featherman \& Pavlou, 2003) and conflict (Hong et al., 2017) when using an innovative technology-based product or service. Consumer privacy practices have indicated their concern about violating privacy disclosure and causing intentional and harmful misuse of personal information collected through travel-sharing applications (Nyshadham, 2000). Moreover, Lee et al. (2017) revealed in their paper that privacy risk is a major threat to consumers, having a critical impact on their acceptance level of innovative technology. Performance risk is defined by Hong et al. (2017) as the consumer's expectation of the performance and benefits of convenience and cost-reduction. Scholars have revealed it to have a negative impact on consumer's BI (Luo et al., 2010; Martins et al., 2014; Park \& Tussyadiah, 2017). The security risk is related to the consumer's perception about the safe transfer of money through online payment services Yang et al. (2015), or the possible harm to property, resources, and personal safety during use of ride-sharing services (Lee et al., 2016; Thakur \& Srivastava, 2014). Lastly, the risk that concerns the lack of unreasonable nature of comprehensive accident compensation mechanisms, aiding financial damage, injury, stress, or time loss caused by a contingency, is called Conflict Risk (Hong, 2017; Wang et al., 2019).

Prior research has revealed that PR has a significant negative impact on PU (Featherman \& Pavlou, 2003; Jarvenpaa et al., 2000; Van der Heijden et al., 2003), and consumer's intention to adopt an innovative technology (Kim et al., 2008; Laforet \& Li, 2005; Wu \& Wang, 2005). In contrast, some researchers have researched the moderating effect of PR on consumer's BI (Chang \& Tseng, 2013; Kwok et al., 2015; Tam, 2012; Wu et al., 2015). Although consumers have many issues related to new technology (Hong, 2017; Schor, 2016), researchers have incorporated the four dimensions of PR, including privacy, performance, security, and conflict, as a moderating variable to assess the impact of consumers' negative perceptions of the use of ride-sharing. Thus, in line with the review of the literature, our research tests the following hypothesis:
"H6: PR moderates the relationship between PEU and BI".

"H7: PR moderates the relationship between $P U$ and $B I$ ".

"H8: PR moderates the relationship between EC and BI". "H9: PR moderates the relationship between EK and BI". "H10: PR moderates the relationship between EA and BI".

\section{Research Model}

The "Technology Acceptance Model (TAM)," which was developed by Davis et al. (1989), has been used as the base of the research model as it provides the appropriate factors for investigating the BI of students regarding ridesharing services. However, the authors have also incorporated environmental triggers into the model to analyze its impact on students' BI. Moreover, perceived risk has also been explored as a moderating variable to determine how it influences students' BI. The developed conceptual model with the incorporated variables can be seen in Fig. 1.

\section{Research Methodology}

\section{Procedure and Sample}

Data collection for analysis for this research was done through a questionnaire survey method. The questionnaire was distributed online to students of higher education. We target the higher education students because of the fact that they face numerous problems due to the mismanagement of the transport system in Karachi. The present transportation system is incapable of meeting the demands of all pupils. It is deadly, unreliable, suffocating, and densely populated. Students face psychological, social, and health issues on a regular basis while traveling. It has imposed severe threats to the education sector, as well as to human life and the environment. Hence, we collected the data from students of higher education by using the convenience sampling approach. This technique is a type of non-probabilistic approaches that rely on data collection from individuals who are readily available to participate in research from the population. The sample size is based on prior studies' recommendations that a sample size of 50 is considered inadequate, a sample size of 300 is considered satisfactory, a sample size of 500 is considered highly suitable, and a sample size of 1000 is considered an exceptional sample size for analysis (Comrey \& Lee, 2013; Hair et al.; 2017; Qazi et al., 2020). Hence our sample size meets the standard as the number of responses collected for data analysis is 441 . We collected the data by sharing it on social networking sites and other mediums; it took approximately 20-25 days in the data collection. 
Fig. 1 Conceptual Model

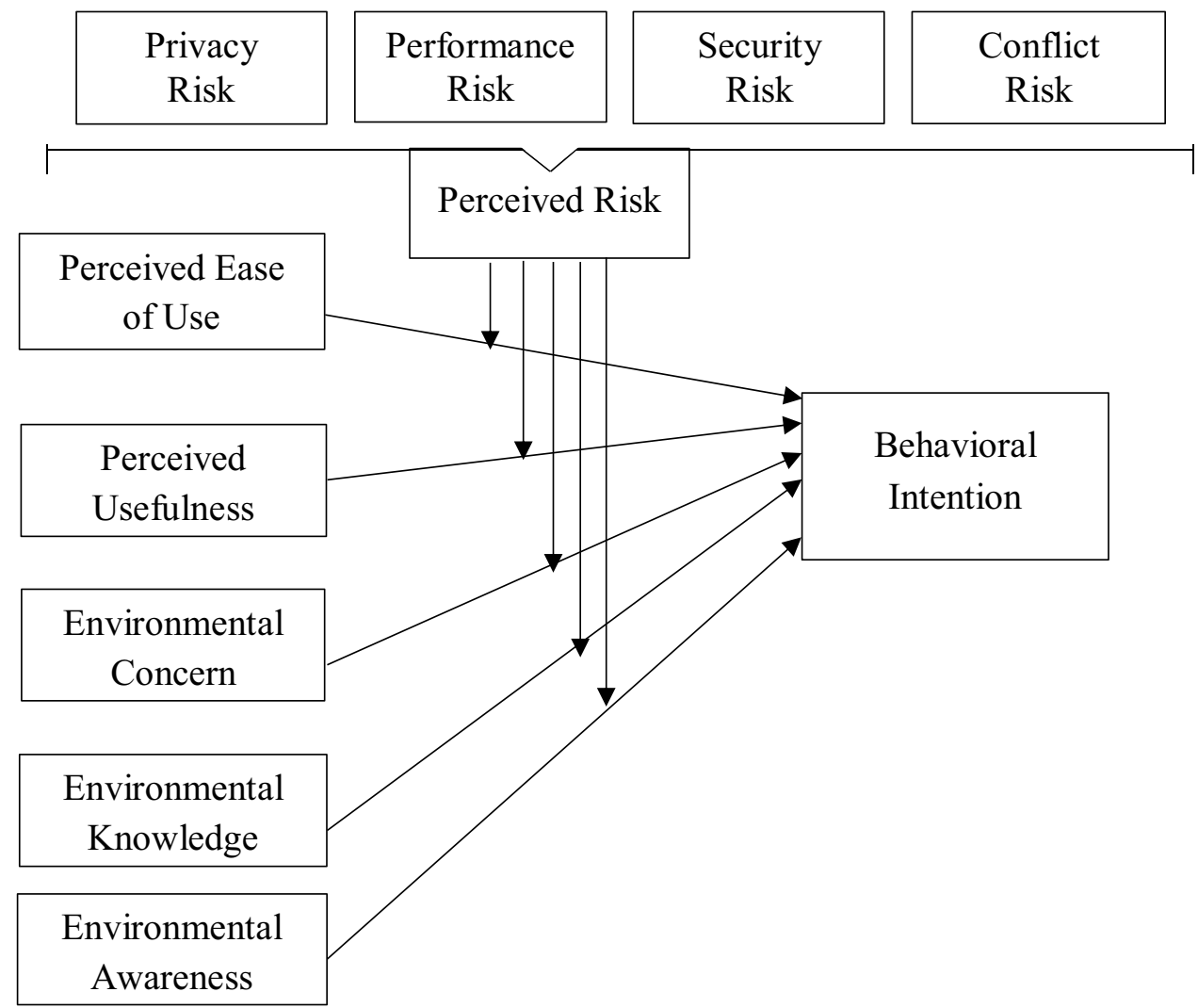

Furthermore, our study's research design is correlational since we aim to identify that either the association between proposed variables is positive or negative.

\section{Research Instruments}

The questionnaire was based on a 5-point Likert scale from "strongly disagree (1) to strongly agree (5)." The questionnaire was adapted from past studies. The scale of PEU, PU, and BI were adapted from prior studies (Gefen et al., 2003; Gefen \& Straub, 2005; Yu et al., 2005). The first item of BI was "I plan to use ride-sharing services," the second item was "I intend to use ride-sharing services." Some sample items of PEU were "It is easy for me to become skillful at using ride-sharing services" and "If I wanted to use ridesharing services, it would be easy to me." The sample items of PU were: "Using ride-sharing services would enable me to get to my destination more quickly" and "Using ridesharing services would improve my commute performance." Additionally, EA was adapted from the study of Wang et al. (2020), the first question of EA was "I am concerned about wasting the resources of our planet," and the second was "I consider the potential environmental impact of my actions when making many of my decisions." The items for measuring EC adapted from the study of Pagiaslis and Krontalis (2014). The sample items of EC were: "I am concerned about the environment" and "I am concerned about pollution." Further, the EK's items were adapted from the prior study of Kaiser et al. (1999) and Carmi et al. (2015). The sample items of EK were: "I feel that I understand the reasons for the various environmental problem" and "I feel that I know the solutions to environmental problems." At last, the items for measuring the four dimensions or PR were adapted from the study of Wang et al. (2019). The sample items were: "It would be risky to disclose my personal information to ride-sharing service facilitators," "I'm concerned that ride-sharing services platform collects too much personal information about me," "Ride-sharing would be insecure," "I'm concerned that share a car with strangers by using ride-sharing services can't ensure my personal and property safety."

\section{Data Analysis and Results}

\section{Demographics}

Based on the demographic information gathered from the collected responses, shown in Table 1, it was found that $77.9 \%$ of responses were from Male students, while $22.2 \%$ of responses were from female students. Furthermore, the ages of the respondents showed that $47.8 \%$ were between the age group of $18-22,45.1 \%$ were between the age group of $23-27,6.6 \%$ were between the age group of $28-32$, and 
Table 1 Respondent's Profile $(N=441)$

\begin{tabular}{lll}
\hline Demographic Items & Frequency & Percentile \\
\hline Gender & & \\
$\quad$ Male & 343 & $77.8 \%$ \\
$\quad$ Female & 98 & $22.2 \%$ \\
Age & & \\
$18-22$ & 211 & $47.8 \%$ \\
$23-27$ & 199 & $45.1 \%$ \\
$28-32$ & 29 & $6.6 \%$ \\
$33-37$ & 2 & $0.5 \%$ \\
Education & & \\
$\quad$ Undergraduate & 239 & $54.2 \%$ \\
Graduate & 202 & $45.8 \%$ \\
\hline
\end{tabular}

Source: Author's Estimations

lastly, $0.5 \%$ were between the age group of 33-37. Finally, the demographic analysis also revealed the educational level of respondents and indicated that the majority of the students were enrolled in Undergraduate programs, specifically $54.2 \%$, while only 45.8 were enrolled in graduate programs.

In this research paper, data analysis was performed using a two-step approach through Smart PLS 3.2.8 software (Ahmed et al., 2021; Ringle et al., 2015). The results were obtained by conducting the PLS-SEM. First, the measurement model was evaluated to test the reliability and validity of the scale. Secondly, the structural model was analyzed to determine the results of the hypotheses. According to Ringle et al. (2005), "Structural Equation Modeling (SEM)" is a valid statistical technique used to measure the validity of a study's theory through the use of statistical facts and figures. In this paper, the authors have deployed a variance-based approach to analyze the hypothetical model. Furthermore, Chin (1998) demonstrated that executing PLS-SEM by using Smart PLS software is an appropriate approach for evaluating and reviewing many integrated models in a variety of research scenarios (Ali \& Raza, 2017; Henseler et al., 2009).

\section{Measurement Model}

A scale's competency is measured through the assessment of the measurement model used for research purposes. It can be determined through analyzing the model's Composite Reliability, Loadings, Cronbach alpha, and the Average Variance Extracted.

Loadings benchmark is set by Churchill Jr (1979), who said that it should be greater than 0.7 ; hence, its values can be seen in Table 2 that they have met the specified benchmark; now it is considered reliable for research (Hair et al., 2014). Cronbach alpha is the measure of internal consistency reliability that assumes the thresholds of 0.7 , which is given by Hair et al. (2014). In Table 2, it can be seen
Table 2 Measurement Model Results

\begin{tabular}{|c|c|c|c|c|c|}
\hline & Items & Loadings & $\begin{array}{l}\text { Cron- } \\
\text { bach's } \\
\text { Alpha }\end{array}$ & $\begin{array}{l}\text { Composite } \\
\text { Reliability }\end{array}$ & $\begin{array}{l}\text { Average } \\
\text { Variance } \\
\text { Extracted }\end{array}$ \\
\hline \multirow[t]{4}{*}{ BI } & BI1 & 0.777 & & & \\
\hline & $\mathrm{BI} 2$ & 0.839 & 0.861 & 0.906 & 0.707 \\
\hline & BI3 & 0.874 & & & \\
\hline & BI4 & 0.870 & & & \\
\hline \multirow[t]{4}{*}{ EA } & EA1 & 0.751 & & & \\
\hline & EA2 & 0.771 & & & \\
\hline & EA3 & 0.822 & 0.799 & 0.869 & 0.625 \\
\hline & EA4 & 0.815 & & & \\
\hline \multirow[t]{3}{*}{$\mathrm{EC}$} & $\mathrm{EC} 1$ & 0.900 & & & \\
\hline & $\mathrm{EC} 2$ & 0.900 & 0.872 & 0.921 & 0.796 \\
\hline & EC3 & 0.876 & & & \\
\hline \multirow[t]{5}{*}{ EK } & EK1 & 0.790 & & & \\
\hline & EK2 & 0.723 & & & \\
\hline & EK3 & 0.739 & 0.846 & 0.885 & 0.608 \\
\hline & EK4 & 0.854 & & & \\
\hline & EK5 & 0.784 & & & \\
\hline \multirow[t]{4}{*}{ PEU } & PEU1 & 0.831 & & & \\
\hline & PEU2 & 0.850 & & & \\
\hline & PEU3 & 0.879 & 0.867 & 0.909 & 0.715 \\
\hline & PEU4 & 0.821 & & & \\
\hline \multirow[t]{7}{*}{ PR } & PRFR1 & 0.868 & & & \\
\hline & PRFR2 & 0.746 & & & \\
\hline & PRIR1 & 0.814 & & & \\
\hline & PRIR2 & 0.874 & 0.913 & 0.926 & 0.643 \\
\hline & SR1 & 0.773 & & & \\
\hline & SR2 & 0.710 & & & \\
\hline & CR1 & 0.816 & & & \\
\hline \multirow[t]{3}{*}{ PU } & PU1 & 0.816 & & & \\
\hline & PU2 & 0.831 & 0.784 & 0.874 & 0.698 \\
\hline & PU3 & 0.858 & & & \\
\hline
\end{tabular}

"Notes: BI=Behavioral Intention, EA=Environmental Awareness, $E C=$ Environmental Concern,$E K=$ Environmental Knowledge, $P E U=$ Perceived Ease of Use, $P R=$ Perceived Risk, $P U=$ Perceived Usefulness"

that the values meet the given criteria. Hence, the scale is determined to be reliable. The composite reliability also evaluates the internal consistency; it states that higher values specify greater levels of reliability. For example, reliability values between " 0.60 and 0.70 " are "acceptable," values between " 0.70 and 0.90 " are "satisfactory to good." Since the values in Table 2 are higher than 0.7 , the criteria for composite reliability has also been met (Raza et al., 2021). Additionally, the analysis shows that every variable has an Average Variance Extract (AVE) value greater than 0.5 ; thus, confirming the scale's convergent validity by meeting the criteria given by Fornell and Larcker (1981). 
Other than that, the discriminant validity is analyzed in Table 3 through the heterotrait-monotrait ratio of correlations (HTMT). The values of HTMT confirm the discriminant validity of the measurement model, as they are less than 0.85 according to the given criteria (Henseler et al., 2015; Raza et al., 2020).

The measurement model proved convergent and discriminant validity. It may now be utilized to determine the subsequent model i.e., "a structural model."

\section{Structural Model}

The current study evaluated the structural model's predictive ability employing bootstrapping and blindfolding procedures through PLS-SEM (Hair et al., 2019). Additionally, the structural model was evaluated using path coefficients, degree of significance, and coefficient of determination (R2), and the model's fit was evaluated using predictive relevance (Q2). The scholar Cohen (1992) claimed that values of R2 are considered substantial at " 0.60 ", moderate at " 0.33 ", and weak at " 0.19 ". The result of existing research shows that R2 is moderate (the value of 0.465 falls within the 0.33-0.60 moderate range) (See Table-4). A blindfolding technique was used to compute Q2 for an additional evaluation. According to Chin's (1988) model, "Q2 > 0" indicates predictive significance, with $0.02,0.15$, and 0.35 indicating weak, medium, and strong predictive relevance, respectively.
The value of the present study depicts that it has a medium predictive relevance as the BI value is greater than 0.15 and less than 0.35, i.e., 0.317. (Table 4).

The structural model analysis was performed using standardized paths to get the results. The results of the path analysis are shown in Table 4 and Fig. 2. Further, the results of the moderating analysis are depicted in Table 5 . The results are discussed based on the criteria "(t-value $>1.96$, $\mathrm{p}$-value $<0.1)^{\prime \prime}$.

\section{Results}

The results of the path analysis are depicted in Table 4. The results revealed that the first path, i.e., (PEU - > BI), is accepted as the association is positive and significant " $(\beta=0.306, p<0.01, \mathrm{t}>1.96)$ ". The second hypothesis (PU - $>\mathrm{BI}$ ) also shows that PU is positively and significantly linked with BI " $(\beta=0.178, p<0.01, \mathrm{t}>1.96)$ ". The next path (EC - > BI) depicts that the association between EC and BI is positive but insignificant as " $(\beta=0.042, p>0.1, \mathrm{t}>1.96)$ ". The fourth hypothesis (EK - $>\mathrm{BI})$ possess a positive and significant association " $(\beta=0.115, p<0.01, \mathrm{t}>1.96)$ ". Another path, i.e., (EA - $>\mathrm{BI})$, is positively and significantly associated with each other as " $(\beta=0.236, p<0.01, \mathrm{t}>1.96)$ ". The next table (Table 5) shows the results of moderating analysis. The following hypotheses (H6, H7, H8, and H10) are not supported because $\mathrm{p}$ values are greater than 0.1 . However,
Table 3 Heterotrait-Monotrait Ratio (HTMT)

\begin{tabular}{llllllll}
\hline & BI & EA & EC & EK & PEU & PR & PU \\
\hline BI & & & & & & \\
EA & 0.607 & & & & & \\
EC & 0.594 & 0.519 & & & & \\
EK & 0.466 & 0.607 & 0.405 & & & \\
PEU & 0.664 & 0.468 & 0.828 & 0.383 & & \\
PR & 0.086 & 0.056 & 0.075 & 0.071 & 0.056 & \\
PU & 0.616 & 0.516 & 0.741 & 0.436 & 0.687 & 0.068 \\
\hline
\end{tabular}

"Notes: BI=Behavioral Intention, EA=Environmental Awareness, EC =Environmental Concern, $E K=$ Environmental Knowledge, PEU =Perceived Ease of Use, PR=Perceived Risk, $P U=$ Perceived Usefulness"

\begin{tabular}{llllllll}
\hline Hypothesis & Regression Path & Effect type & $\beta$-Coeff & $\begin{array}{l}\text { Standard } \\
\text { Deviation }\end{array}$ & T Statistics & P-values & Remarks \\
\hline H1 & PEU - > BI & Direct Effect & 0.306 & 0.070 & 4.426 & 0.000 & Supported \\
H2 & PU - > BI & Direct Effect & 0.178 & 0.061 & 2.828 & 0.005 & Supported \\
H3 & EC - > BI & Direct Effect & 0.042 & 0.079 & 0.488 & 0.626 & Not Supported \\
H4 & EK - > BI & Direct Effect & 0.115 & 0.047 & 2.528 & 0.012 & Supported \\
H5 & EA - > BI & Direct Effect & 0.236 & 0.063 & 3.836 & 0.000 & Supported \\
$R^{2}$ (Behavioral Intention $)=0.465$ & & & & & \\
$Q^{2}$ (Behavioral Intention $)=0.317$ & & & & & \\
\hline
\end{tabular}


Fig. 2 Results of Path Analysis

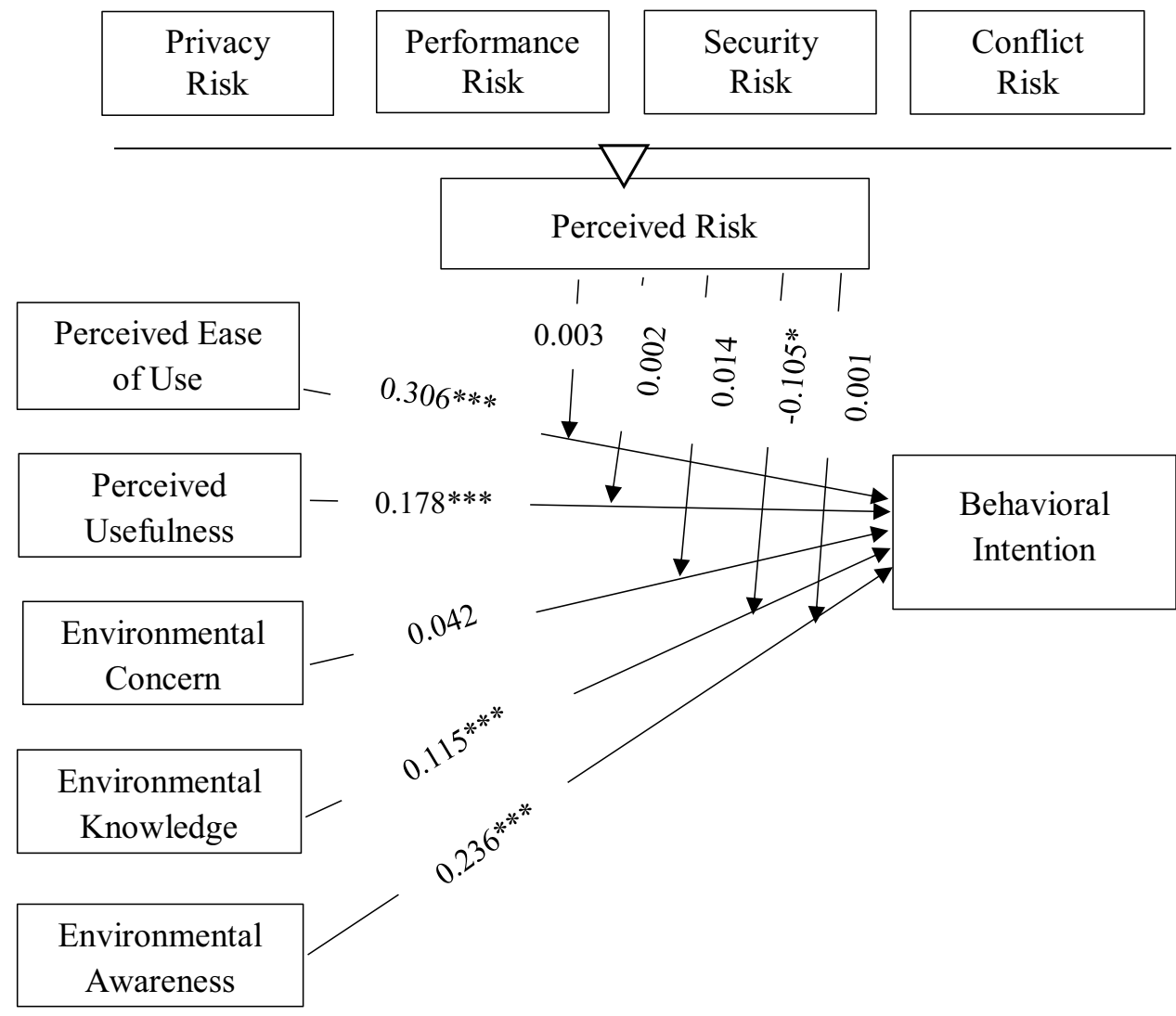

Table 5 Moderating Effect of Perceived Risk

\begin{tabular}{llllllll}
\hline Hypothesis & Regression Path & Effect type & $\beta$-Coeff & $\begin{array}{l}\text { Standard } \\
\text { Devia- } \\
\text { tion }\end{array}$ & T Statistics & P-values & Remarks \\
\hline H6 & PEU - > BI & Indirect Effect & 0.003 & 0.070 & 0.090 & 0.928 & Not Supported \\
H7 & PU - > BI & Indirect Effect & 0.002 & 0.069 & 0.141 & 0.888 & Not Supported \\
H8 & EC - > BI & Indirect Effect & 0.014 & 0.075 & 0.460 & 0.646 & Not Supported \\
H9 & EK - > BI & Indirect Effect & -0.105 & 0.057 & 1.958 & 0.051 & Supported \\
H10 & EA - > BI & Indirect Effect & 0.001 & 0.063 & 0.045 & 0.964 & Not Supported
\end{tabular}

"Notes: BI=Behavioral Intention, EA=Environmental Awareness, EC=Environmental Concern, $E K=$ Environmental Knowledge, $P E U=$ Perceived Ease of Use, $P R=$ Perceived Risk, $P U=$ Perceived Usefulness" results portray that PR plays a crucial role in reducing students' BI. In contrast, H9 is supported because PR weakens the association between EK and BI " $(\beta=-0.105, p<0.1)$ ”.

\section{Discussion}

The hypotheses tests have shown that the relationship between PEU and BI and PU and BI is found to be positively significant. These results are consistent with the previous studies (Davis, 1989; Cheng \& Huang, 2013; Davis et al., 1989; Tan et al., 2014; Chin \& Todd, 1995; Mallat et al., 2009; Nikou \& Economides, 2017; Park et al., 2014). This means that the benefits and its convenient process influence a students' BI regarding ride-sharing services. Thus, H1 and $\mathrm{H} 2$ have been accepted. So, when students observe that ride-sharing services are easy to use, accessible, reliable, and convenient for daily use, they will prefer ride-sharing services instead of local transportation.

On the contrary, the third path results showed that the relationship between $\mathrm{EC}$ and $\mathrm{BI}$ is positive but insignificant. This means that students' concern for the environment is not a strong predictor of their BI to use ride-sharing services. These results contradict the findings of Alwitt and Berger (1993), Kalafatis et al. (1999), and Schwepker and Cornwell (1991). Based on the results, we conclude that students will not use ride-sharing services because of EC. Though the 
association is positive, it does not have a major role in fostering students' BI.

The next hypotheses, i.e., $\mathrm{H} 4$ and $\mathrm{H} 5$, are also accepted because findings depict that EK and EA are positively associated with BI. It means that knowledge and awareness about the environment strongly impact students' BI to use ride-sharing services. The findings are consistent with prior research (Tilikidou \& Delistavrou, 2006; Tanner et al., 2004; Fishman et al., 2013; Tanner \& Wölfing Kast, 2003; Ellen, 1994; Kahn, 2007; Bansal, 2011; Chen \& Hung, 2016). Students with higher EK and EA are more likely to depict positive BI. Currently, the rapid environmental degradation, climate change, and increasing carbon emissions are alarming for all countries. Hence, competent authorities, marketers, organizations, and media spread awareness among people who boost their knowledge. When students have enough knowledge about the environment and are aware of the deteriorating facts, they will ultimately participate in eco-friendly activities that might reduce pollution. As ridesharing services help reduce travel expenses, pollution, and traffic (Wang et al., 2019; Wang et al., 2020). So, students will depict a positive BI towards a sustainable transportation system.

Furthermore, the results of the moderating analysis are shown in Table 5, where the moderating effect of PR is analyzed. Based on the findings, it is stated that PR negatively moderates the association between EK and BI. It means that when students are highly concerned about the risks of ridesharing services so, despite environmental knowledge, they will depict negative behavioral intention because of the risk (Pelaez et al., 2019; Yi et al., 2020). On the other hand, PR does not weaken the relationship between (PEU - > BI), (PU - > BI), (EC - > BI), and (EA - > BI). Thus, the findings contradict the hypotheses made by the authors. The results reveal that PR positively moderates the associations, but all are insignificant. Hence, it means that PR can affect students' BI. In a developing country like Pakistan, people are more exposed to various risks. So, non-users are reluctant to depict positive behavior when they identify a risk. It is necessary to offer secure services to users so that they can start using ride-sharing services.

\section{Conclusion, Recommendations, and Limitations}

\section{Conclusion}

Ride-sharing is an innovative transportation model and an important aspect of the sharing economy because of the many sustainable benefits it offers to passengers, society, traffic, and the environment. This paper explored the factors that influence a students' BI toward the use of ride-sharing services. The factors explored are taken from the TAM, while environmental factors have also been incorporated to determine the effects of environmental triggers on the students' BI in Pakistan. In addition, the study also included $\mathrm{PR}$ as a moderating variable to analyze its impact on the relationship between the constructs developed. As expected, the link of PEU, PU, EK, and EA with students' BI is found to be positive and significant. In contrast, the findings indicated that the link between environmental concern and $\mathrm{BI}$ is positive but insignificant. The reason behind this association is that even ride-sharing services are responsible for pollution, which indicates that students would prefer alternative modes of transportation that do not harm the environment. Meanwhile, the results showed that PR negatively moderates the association of EK and BI. Moreover, in the case of other paths, PR has a positive moderating effect, but it is insignificant.

\section{Practical Implications}

This study's findings contribute to the literature in the area of sharing economy by identifying predictors of ride-sharing service BI among the students of higher education. This provides useful information to policymakers and ride-sharing service providers to improve ride-sharing services for consumers. In addition, to ensure that people can adopt the sustainable means of the transport system. Since the findings show that the PU and PEU is a strong predictor of $\mathrm{BI}$, measures can be taken to make ride-sharing more convenient and beneficial for customers to influence their BI positively. For instance, an application of ride-sharing services should be user-friendly. So that while booking the ride, students do not face issues, and it does not take much time. In addition, service providers can share the video tutorials on their social media pages and websites that explain how to book a ride, the benefits of ride-sharing, and how students can avail it. Another way is to target television commercials to spread awareness. It will help consumers to learn about online ridesharing services applications and benefits more easily. Furthermore, the service providers should ensure that their team and staff members are rightly trained and well-mannered as staff members (such as drivers, operators, and receptionists) are the front-line employees, so they should resolve queries and inform the consumers about services. Additionally, campaigns can be started at different universities to spread awareness and convey the usefulness of online ride-sharing services. These practices help users understand the technology more easily; hence, allowing students to perceive that technology is easy to use and useful.

The other recommendation is to work towards providing means of gaining EK and creating EA of the potential environmental benefits of ride-sharing among students, as it has a significant impact on BI. The utmost responsibility 
of spreading environmental knowledge lies on the shoulders of the government. The environment is changing rapidly and affecting humans lives. Hence, the government should promote eco-friendly businesses to reduce environmental degradation. As results reveal that EK and EA foster students' behavioral intention towards ride-sharing services. So, competitive authorities must explain different ways through which users can help in mitigating pollution. Once people learn the hazardous effects of increasing traffic congestion and pollution, they will ultimately start using ridesharing services. Additionally, service providers should also highlight the environmental benefits in their campaigns and marketing activities. People with greater knowledge and awareness will be more likely to depict positive behavior.

Besides that, PR should be reduced by taking relevant safety precautions and elaborating on the safety measures in case of a contingency. Furthermore, ride-sharing platforms must set out criteria for the use of personal data and their authority to access their data transparently to their various customers to minimize perceived privacy risks. Performance risk can be reduced through effective measures of driver licensing and certification and proper evaluation of vehicles to ensure they meet the proper safety standards. To ensure the ultimate security of consumers, ride-sharing service providers should deploy driver-tracking and rating systems, provide proper training for the best customer experience, and strictly audit the drivers' backgrounds. In addition, adequate compensation policies should be implemented to reduce the perceived risk of conflict between customers. In the same way, adequate insurance cover should also be provided to both parties concerned. Lastly, ride-sharing service providers should publicize all the developed safety measures appropriately to improve customers' perception of risks involved in ride-sharing.

\section{Theoretical Contributions}

The present research findings have contributed to the existing body of knowledge in various ways. The first contribution is the use of TAM in understanding the behavioral intention of ride-sharing services in the context of a developing country, Pakistan. Secondly, no one has studied the combination of TAM and environmental triggers under the same framework; thus, it provides an in-depth analysis about students' behavior that either perceived ease of use, perceived usefulness, or environmental triggers (concern, knowledge, and awareness) foster students' behavioral intention. Finally, the current research has contributed to the literature by revealing that people might positively use technology if they hold enough environmental knowledge and awareness. However, along with environmental benefits, it is necessary not to forget the risk that might affect the students' behavioral intention. Therefore, perceived risk has been incorporated as the moderating variable in the research framework. It explains how perceived risk can affect people's behavioral intention despite easiness and environmental knowledge.

\section{Limitations of the Research}

The present research has the following limitations: first, the study targeted higher education students located in Karachi, Pakistan. Second, the authors evaluate the direct association between independent variables (PEU, PU, EC, EK, and $\mathrm{EA})$ and dependent variable (BI) along with the moderating analysis under the framework of the TAM model only. Third, the research is solely based on the quantitative approach. Last, the main focus of the research was the non-users. However, the ride-sharing behavior of users can be evaluated because it will provide an insight into the growth of online ride-sharing services.

\section{Future Recommendations}

Even though this research provides substantial findings that offer essential practical and theoretical implications, it is subject to several limitations that need to be acknowledged to overcome in future studies. The first recommendation is to target the students of other cities as well. Secondly, future researchers can conduct the same research by adopting a mixed-method approach, i.e., quantitative and qualitative. Third, it is recommended to study the same research model in two different countries and conduct a comparative analysis. For example, compare developed and developing countries or compare two developing countries such as Pakistan and Bangladesh. Fourth, other mediating and moderating factors can also be added to extend the model further and identify predictors of ride-sharing behavior. Such as government support, inflation, green values, and price value can be incorporated as moderators, and consumers' attitudes can be used as a mediator. At last, future researchers can increase independent variables. For instance, the research framework can add constructs of the "Unified theory of acceptance and use of technology" (performance expectancy, hedonic motivation, social influence, facilitating conditions, and effort expectancy).

Funding Funding information is not applicable / No funding was received.

\section{Declarations}

Ethics Approval and Consent to Participate Not applicable.

Consent for Publication Not applicable. 
Conflict of Interest The authors declare that they have no conflict of interest.

\section{References}

Abd Elmeguid, S. M., Ragheb, M. A., Tantawi, P. I., \& Elsamadicy, A. M. (2018). Customer satisfaction in sharing economy the case of ridesharing service in Alexandria. Egypt. The Business \& Management Review, 9(4), 373-382.

Agatz, N., Erera, A. L., Savelsbergh, M. W., \& Wang, X. (2011). Dynamic ride-sharing: A simulation study in metro Atlanta. Procedia-Social and Behavioral Sciences, 17, 532-550.

Agatz, N., Erera, A., Savelsbergh, M., \& Wang, X. (2012). Optimization for dynamic ride-sharing: A review. European Journal of Operational Research, 223(2), 295-303.

Ahmed, M., Zehou, S., Raza, S. A., Qureshi, M. A., \& Yousufi, S. Q. (2020). Impact of CSR and environmental triggers on employee green behavior: The mediating effect of employee well-being. Corporate Social Responsibility and Environmental Management, 27(5), 2225-2239.

Ahmed, M., Guo, Q., Qureshi, M. A., Raza, S. A., Khan, K. A., \& Salam, J. (2021). Do green HR practices enhance green motivation and proactive environmental management maturity in hotel industry? International Journal of Hospitality Management, 94, 102852.

Akbari, M., Moradi, A., SeyyedAmiri, N., Zúñiga, M. Á., Rahmani, Z., \& Padash, H. (2020). Consumers' intentions to use ridesharing services in Iran. Research in Transportation Business \& Management, 100616.

Ali, M., \& Raza, S. A. (2017). Service quality perception and customer satisfaction in Islamic banks of Pakistan: The modified SERVQUAL model. Total Quality Management \& Business Excellence, 28(5-6), 559-577.

Alwitt, L. F., \& Berger, I. E. (1993). Understanding the link between environmental attitudes and consumer product usage: Measuring the moderating role of attitude strength. Advances in Consumer Research, 20(1).

Bang, H. K., Ellinger, A. E., Hadjimarcou, J., \& Traichal, P. A. (2000). Consumer concern, knowledge, belief, and attitude toward renewable energy: An application of the reasoned action theory. Psychology \& Marketing, 17(6), 449-468.

Bansal, G. (2011). E-book usage: Role of environmental consciousness, personality and past usage. Journal of Computer Information Systems, 52(2), 93-104.

Bauer, R. A. (1960). Consumer behavior as risk taking. , 384-398.

Carmi, N., Arnon, S., \& Orion, N. (2015). Transforming environmental knowledge into behavior: The mediating role of environmental emotions. The Journal of Environmental Education, 46(3), 183-201.

Caulfield, B. (2009). Estimating the environmental benefits of ridesharing: A case study of Dublin. Transportation Research Part D: Transport and Environment, 14(7), 527-531.

Chang, E. C., \& Tseng, Y. F. (2013). Research note: E-store image, perceived value and perceived risk. Journal of Business Research, 66(7), 864-870.

Chen, S. C., \& Hung, C. W. (2016). Elucidating the factors influencing the acceptance of green products: An extension of theory of planned behavior. Technological Forecasting and Social Change, $112,155-163$.

Chen, S. Y., \& Lu, C. C. (2016). A model of green acceptance and intentions to use bike-sharing: YouBike users in Taiwan. Networks and Spatial Economics, 16(4), 1103-1124.
Cheng, M. (2016). Sharing economy: A review and agenda for future research. International Journal of Hospitality Management, 57, 60-70.

Cheng, Y. H., \& Huang, T. Y. (2013). High speed rail passengers' mobile ticketing adoption. Transportation Research Part C: Emerging Technologies, 30, 143-160.

Cheung, R., \& Vogel, D. (2013). Predicting user acceptance of collaborative technologies: An extension of the technology acceptance model for e-learning. Computers \& Education, 63, 160-175.

Chin, W. W. (1998). The partial least squares approach to structural equation modeling. Modern Methods for Business Research, 295(2), 295-336.

Chin, W. W., \& Todd, P. A. (1995). On the use, usefulness, and ease of use of structural equation modeling in MIS research: A note of caution. MIS Quarterly, 237-246.

Churchill Jr., G. A. (1979). A paradigm for developing better measures of marketing constructs. Journal of Marketing Research, 16(1), 64-73.

Comrey, A. L., \& Lee, H. B. (2013). A first course in factor analysis. Psychology Press.

Davis, F. D. (1989). Perceived usefulness, perceived ease of use, and user acceptance of information technology. MIS quarterly, 319-340.

Davis, F. D., Bagozzi, R. P., \& Warshaw, P. R. (1989). User acceptance of computer technology: A comparison of two theoretical models. Management Science, 35(8), 982-1003.

Daziano, R. A., \& Bolduc, D. (2013). Incorporating pro-environmental preferences towards green automobile technologies through a Bayesian hybrid choice model. Transportmetrica A: Transport Science, 9(1), 74-106.

Dillahunt, T. R., \& Malone, A. R. (2015). The promise of the sharing economy among disadvantaged communities. In proceedings of the 33rd annual ACM conference on human factors in computing systems (pp. 2285-2294).

Dong, Y., Wang, S., Li, L., \& Zhang, Z. (2018). An empirical study on travel patterns of internet based ride-sharing. Transportation research part C: emerging technologies, 86, 1-22.

Ellen, P. S. (1994). Do we know what we need to know? Objective and subjective knowledge effects on pro-ecological behaviors. Journal of Business Research, 30(1), 43-52.

Faize, F. A., \& Akhtar, M. (2020). Addressing environmental knowledge and environmental attitude in undergraduate students through scientific argumentation. Journal of Cleaner Production, 252, 119928 .

Farooqi, Z. U. R., Sabir, M., Latif, J., Aslam, Z., Ahmad, H. R., Ahmad, I., et al. (2020). Assessment of noise pollution and its effects on human health in industrial hub of Pakistan. Environmental Science and Pollution Research, 27(3), 2819-2828.

Featherman, M. S., \& Pavlou, P. A. (2003). Predicting e-services adoption: A perceived risk facets perspective. International Journal of Human-Computer Studies, 59(4), 451-474.

Feeney, M. (2015). Is ride-sharing safe?. Cato Institute Policy Analysis, (767).

Fellows, N. T., \& Pitfield, D. E. (2000). An economic and operational evaluation of urban car-sharing. Transportation Research Part D: Transport and Environment, 5(1), 1-10.

Fishman, E., Washington, S., \& Haworth, N. (2013). Bike share: A synthesis of the literature. Transport Reviews, 33(2), 148-165.

Fleischer, A., \& Wåhlin, C. (2016). Want to take a ride with me?: The Intention of Generation Y to Use Uber.

Fransson, N., \& Gärling, T. (1999). Environmental concern: Conceptual definitions, measurement methods, and research findings. Journal of Environmental Psychology, 19(4), 369-382.

Frenken, K., \& Schor, J. (2019). Putting the sharing economy into perspective. In A Research Agenda for Sustainable Consumption Governance. Edward Elgar Publishing. 
Fornell, C., \& Larcker, D. F. (1981). Structural equation models with unobservable variables and measurement error: Algebra and statistics.

Fujii, S. (2006). Environmental concern, attitude toward frugality, and ease of behavior as determinants of pro-environmental behavior intentions. Journal of Environmental Psychology, 26(4), 262-268.

Furuhata, M., Dessouky, M., Ordóñez, F., Brunet, M. E., Wang, X., \& Koenig, S. (2013). Ridesharing: The state-of-the-art and future directions. Transportation Research Part B: Methodological, 57, 28-46.

Gefen, D., Karahanna, E., \& Straub, D. W. (2003). Trust and TAM in online shopping: An integrated model. MIS quarterly, 51-90.

Gefen, D., \& Straub, D. (2005). A practical guide to factorial validity using PLS-graph: Tutorial and annotated example. Communications of the Association for Information Systems, 16(1), 5.

Jarvenpaa, S. L., Tractinsky, N., \& Vitale, M. (2000). Consumer trust in an internet store. Information Technology and Management, $1(1-2), 45-71$.

Ha, S., \& Stoel, L. (2009). Consumer e-shopping acceptance: Antecedents in a technology acceptance model. Journal of Business Research, 62(5), 565-571.

Hair, J., Hollingsworth, C. L., Randolph, A. B., \& Chong, A. Y. L. (2017). An updated and expanded assessment of PLS-SEM in information systems research. Industrial Management \& Data Systems, 117(3), 442-458. https://doi.org/10.1108/ IMDS-04-2016-0130.

Hair, J. F., Risher, J. J., Sarstedt, M., \& Ringle, C. M. (2019). When to use and how to report the results of PLSSEM. European Business Review, 31(1), 2-24. https://doi.org/10.1108/EBR-11-2018-0203.

Hamari, J., Sjöklint, M., \& Ukkonen, A. (2016). The sharing economy: Why people participate in collaborative consumption. Journal of the Association for Information Science and Technology, 67(9), 2047-2059.

Hansen, E. G., Gomm, M. L., Bullinger, A. C., \& Moslein, K. M. (2010). A community-based toolkit for designing ride-sharing services: The case of a virtual network of ride access points in Germany. International Journal of Innovation and Sustainable Development, 5(1), 80-99.

Heinrichs, H. (2013). Sharing economy: A potential new pathway to sustainability. GAIA-Ecological Perspectives for Science and Society, 22(4), 228-231.

Henseler, J., Ringle, C. M., \& Sinkovics, R. R. (2009). The use of partial least squares path modeling in international marketing. In New challenges to international marketing. Emerald Group Publishing Limited.

Henseler, J., Ringle, C. M., \& Sarstedt, M. (2015). A new criterion for assessing discriminant validity in variance-based structural equation modeling. Journal of the Academy of Marketing Science, 43(1), 115-135.

Hong, S. J. (2017). Assessing economic value of reducing perceived risk in the sharing economy: The case of ride-sharing services.

Hong, Z., Chen, Y., Mahmassani, H. S., \& Xu, S. (2017). Commuter ride-sharing using topology-based vehicle trajectory clustering: Methodology, application and impact evaluation. Transportation Research Part C: Emerging Technologies, 85, 573-590.

Hopwood, B., Mellor, M., \& O'Brien, G. (2005). Sustainable development: Mapping different approaches. Sustainable Development, 13(1), 38-52.

Hubert, M., Blut, M., Brock, C., Backhaus, C., \& Eberhardt, T. (2017). Acceptance of smartphone-based Mobile shopping: Mobile benefits, customer characteristics, perceived risks, and the impact of application context. Psychology \& Marketing, 34(2), 175-194.

Hwang, J., \& Griffiths, M. A. (2017). Share more, drive less: Millennials value perception and behavioral intent in using collaborative consumption services. Journal of Consumer Marketing.
Kahn, M. E. (2007). Do greens drive hummers or hybrids? Environmental ideology as a determinant of consumer choice. Journal of Environmental Economics and Management, 54(2), 129-145.

Kaiser, F. G., Wölfing, S., \& Fuhrer, U. (1999). Environmental attitude and ecological behaviour. Journal of Environmental Psychology, 19(1), 1-19.

Kalafatis, S. P., Pollard, M., East, R., \& Tsogas, M. H. (1999). Green marketing and Ajzen's theory of planned behaviour: A crossmarket examination. Journal of Consumer Marketing, 16(5), $441-460$.

Kelly, K. L. (2007). Casual carpooling-enhanced. Journal of Public Transportation, 10(4), 6.

Kim, D. J., Ferrin, D. L., \& Rao, H. R. (2008). A trust-based consumer decision-making model in electronic commerce: The role of trust, perceived risk, and their antecedents. Decision Support Systems, 44(2), 544-564.

Kwok, M. L. J., Wong, M. C. M., \& Lau, M. M. (2015). Examining how environmental concern affects purchase intention: Mediating role of perceived trust and moderating role of perceived risk. Contemporary Management Research, 11(2).

Laforet, S., \& Li, X. (2005). Consumers' attitudes towards online and mobile banking in China. International journal of bank marketing.

Lee, C., Rahafrooz, M., \& Lee, O. K. D. (2017). What are the concerns of using a ride-sharing service?: An investigation of Uber.

Lee, M. C. (2009). Factors influencing the adoption of internet banking: An integration of TAM and TPB with perceived risk and perceived benefit. Electronic Commerce Research and Applications, 8(3), 130-141.

Lee, Z. W., Chan, T. K., Balaji, M. S., \& Chong, A. Y. L. (2016, June). Technology-mediated sharing economy: Understanding user participation in collaborative consumption through the benefit-cost perspective. In proceedings of the 20th Pacific Asia conference on information systems (PACIS).

Legris, P., Ingham, J., \& Collerette, P. (2003). Why do people use information technology? A critical review of the technology acceptance model. Information \& Management, 40(3), 191-204.

Liao, Q., Luo, X. R., Gurung, A., \& Shi, W. (2015). A holistic understanding of non-users' adoption of universitycampus wireless network: An empirical investigation. Computers in Human Behavior, 49, 220-229.

Liu, J., Kockelman, K. M., Boesch, P. M., \& Ciari, F. (2017). Tracking a system of shared autonomous vehicles across the Austin, Texas network using agent-based simulation. Transportation, 44(6), 1261-1278.

Liu, X., \& Wei, K. K. (2003). An empirical study of product differences in consumers' E-commerce adoption behavior. Electronic Commerce Research and Applications, 2(3), 229-239.

Lokhandwala, M., \& Cai, H. (2018). Dynamic ride sharing using traditional taxis and shared autonomous taxis: A case study of NYC. Transportation Research Part C: Emerging Technologies, 97, $45-60$.

Luo, X., Li, H., Zhang, J., \& Shim, J. P. (2010). Examining multidimensional trust and multi-faceted risk in initial acceptance of emerging technologies: An empirical study of mobile banking services. Decision Support Systems, 49(2), 222-234.

Mac Callum, K., \& Jeffrey, L. K. (2014). Factors impacting teachers' adoption of mobile learning. Journal of Information Technology Education Research, 13, 141-162.

Mallat, N., Rossi, M., Tuunainen, V. K., \& Öörni, A. (2009). The impact of use context on mobile services acceptance: The case of mobile ticketing. Information \& Management, 46(3), 190-195.

Martins, C., Oliveira, T., \& Popovič, A. (2014). Understanding the internet banking adoption: A unified theory of acceptance and use of technology and perceived risk application. International Journal of Information Management, 34(1), 1-13. 
Meelen, T., \& Frenken, K. (2015). Stop saying Uber is part of the sharing economy. Fast Company, 14.

Minett, P., \& Pearce, J. (2011). Estimating the energy consumption impact of casual carpooling. Energies, 4(1), 126-139.

Mostafa, M. M. (2007). A hierarchical analysis of the green consciousness of the Egyptian consumer. Psychology \& Marketing, 24(5), 445-473.

Munir, S., Khan, S., Nazneen, S., \& Ahmad, S. S. (2021). Temporal and seasonal variations of noise pollution in urban zones: A case study in Pakistan. Environmental Science and Pollution Research, 1-9.

Nikou, S. A., \& Economides, A. A. (2017). Mobile-based assessment: Integrating acceptance and motivational factors into a combined model of self-determination theory and technology acceptance. Computers in Human Behavior, 68, 83-95.

Nyshadham, E. A. (2000). Consumer perceptions of online transaction security-A cognitive explanation of the origins of perception. AMCIS 2000 Proceedings, 111.

Pagiaslis, A., \& Krontalis, A. K. (2014). Green consumption behavior antecedents: Environmental concern, knowledge, and beliefs. Psychology \& Marketing, 31(5), 335-348.

Park, C. K., Kim, H. J., \& Kim, Y. S. (2014). A study of factors enhancing smart grid consumer engagement. Energy Policy, 72, 211-218.

Park, S., \& Tussyadiah, I. P. (2017). Multi-dimensional facets of perceived risk in mobile travel booking. Journal of Travel Research, 56(7), 854-867.

Paundra, J., van Dalen, J., Rook, L., \& Ketter, W. (2020). Ridesharing platform entry effects on ownership-based consumption in Indonesia. Journal of Cleaner Production, 265, 121535.

Pelaez, A., Chen, C. W., \& Chen, Y. X. (2019). Effects of perceived risk on intention to purchase: A meta-analysis. Journal of Computer Information Systems, 59(1), 73-84.

Prieto, L. P., Tchounikine, P., Asensio-Pérez, J. I., Sobreira, P., \& Dimitriadis, Y. (2014). Exploring teachers' perceptions on different CSCL script editing tools. Computers \& Education, 78, 383-396.

Qazi, W., Raza, S. A., \& Khan, K. A. (2020). The contradiction between self-protection and self-presentation on knowledge sharing behaviour: Evidence from higher education students in Pakistan. International Journal of Knowledge and Learning, 13(3), 246-271.

Rasheed, Gaber, H., \& Elsamadicy, A. M. (2021). What drives customers to continue using ride-sharing apps during the COVID-19 pandemic? The case of Uber in Egypt. Cogent Business \& Management, 8(1), 1944009.

Raza, S. A., Qazi, W., Umer, B., \& Khan, K. A. (2020). Influence of social networking sites on life satisfaction among university students: A mediating role of social benefit and social overload. Health Education, 120(2), 141-164. https://doi.org/10.1108/ HE-07-2019-0034

Raza, S. A., Qazi, W., Khan, K. A., \& Salam, J. (2021). Social isolation and acceptance of the learning management system (LMS) in the time of COVID-19 pandemic: An expansion of the UTAUT model. Journal of Educational Computing Research, 59(2), 183-208.

Ringle, C. M., Wende, S., \& Becker, J. M. (2015). SmartPLS 3. SmartPLS GmbH, Boenningstedt. Journal of Service Science And Management, 10(3).

Ringle, C. M., Wende, S., \& Will, A. (2005). SmartPLS 2.0 M3 Beta.

Rustam, A., Wang, Y., \& Zameer, H. (2020). Environmental awareness, firm sustainability exposure and green consumption behaviors. Journal of Cleaner Production, 268, 122016.

Schor, J. (2016). Debating the sharing economy. Journal of Self-Governance and Management Economics, 4(3), 7-22.

Schwepker, C. H., \& Cornwell, B. T. (1991). An examination of ecologically concerned consumers and their intention to purchase ecologically packaged goods. Journal of Public Policy \& Marketing, 10, 77-101.

Schuitema, G., Anable, J., Skippon, S., \& Kinnear, N. (2013). The role of instrumental, hedonic and symbolic attributes in the intention to adopt electric vehicles. Transportation Research Part A: Policy and Practice, 48, 39-49.

Schwartz, S. H. (1977). Normative influences on altruism. Advances in Experimental Social Psychology, 10(1), 221-279.

Shah, P., Varghese, V., Jana, A., \& Mathew, T. (2020). Analysing the ride sharing behaviour in ICT based cab services: A case of Mumbai, India. Transportation Research Procedia, 48, 233-246.

Shaheen, S. A., Cohen, A. P., \& Roberts, J. D. (2006). Carsharing in North America: Market growth, current developments, and future potential. Transportation Research Record, 1986(1), 116-124.

Shaheen, S. A., Mallery, M. A., \& Kingsley, K. J. (2012). Personal vehicle sharing services in North America. Research in Transportation Business \& Management, 3, 71-81.

Straub, D. W. (1989). Validating instruments in MIS research. MIS Quarterly, 147-169.

Tam, J. L. M. (2012). The moderating role of perceived risk in loyalty intentions: An investigation in a service context. Marketing Intelligence \& Planning.

Tan, G. W. H., Ooi, K. B., Leong, L. Y., \& Lin, B. (2014). Predicting the drivers of behavioral intention to use mobile learning: A hybrid SEM-neural networks approach. Computers in Human Behavior, 36, 198-213.

Tanner, C., Kaiser, F. G., \& WÖfing Kast, S. (2004). Contextual conditions of ecological consumerism: A food-purchasing survey. Environment and Behavior, 36(1), 94-111.

Tanner, C., \& Wölfing Kast, S. (2003). Promoting sustainable consumption: Determinants of green purchases by Swiss consumers. Psychology \& Marketing, 20(10), 883-902.

Teubner, T., \& Flath, C. M. (2015). The economics of multi-hop ride sharing. Business \& Information Systems Engineering, 57(5), 311-324.

Thakur, R., \& Srivastava, M. (2014). Adoption readiness, personal innovativeness, perceived risk and usage intention across customer groups for mobile payment services in India. Internet Research.

Tilikidou, I., \& Delistavrou, A. (2006). Are Greeks knowledgeable enough about environmental issues. In 10th international conference of the Thessaloniki economic society, Thessaloniki (pp. 9-11).

Van der Heijden, H., Verhagen, T., \& Creemers, M. (2003). Understanding online purchase intentions: Contributions from technology and trust perspectives. European Journal of Information Systems, 12(1), 41-48.

Venkatesh, V., \& Davis, F. D. (2000). A theoretical extension of the technology acceptance model: Four longitudinal field studies. Management Science, 46(2), 186-204.

Wang, S., Fan, J., Zhao, D., Yang, S., \& Fu, Y. (2016). Predicting consumers' intention to adopt hybrid electric vehicles: Using an extended version of the theory of planned behavior model. Transportation, 43(1), 123-143.

Wang, Y., Zheng, B., \& Lim, E. P. (2018). Understanding the effects of taxi ride-sharing-A case study of Singapore. Computers, Environment and Urban Systems, 69, 124-132.

Wang, Y., Gu, J., Wang, S., \& Wang, J. (2019). Understanding consumers' willingness to use ride-sharing services: The roles of perceived value and perceived risk. Transportation Research Part C: Emerging Technologies, 105, 504-519.

Wang, Y., Wang, S., Wang, J., Wei, J., \& Wang, C. (2020). An empirical study of consumers' intention to use ride-sharing services: Using an extended technology acceptance model. Transportation, 47(1), 397-415. 
Wu, J. H., \& Wang, S. C. (2005). What drives mobile commerce? An empirical evaluation of the revised technology acceptance model. Information \& Management, 42(5), 719-729.

Wu, W. Y., Chen, S. H., \& Lu, H. Y. (2015). The Moderating Roles of Perceived Risks and Social Influences with Regard to the Effects of Consumers' Perceived Value and Online Purchasing. In Proceedings of the 2010 Academy of Marketing Science (AMS) Annual Conference (pp. 269-273). Springer.

Yang, Q., Pang, C., Liu, L., Yen, D. C., \& Tarn, J. M. (2015). Exploring consumer perceived risk and trust for online payments: An empirical study in China's younger generation. Computers in Human Behavior, 50, 9-24.

Yi, J., Yuan, G., \& Yoo, C. (2020). The effect of the perceived risk on the adoption of the sharing economy in the tourism industry: The case of Airbnb. Information Processing \& Management, 57(1), 102108.

Yin, B., Liu, L., Coulombel, N., \& Viguie, V. (2018). Appraising the environmental benefits of ride-sharing: The Paris region case study. Journal of Cleaner Production, 177, 888-898.
Yu, J., Ha, I., Choi, M., \& Rho, J. (2005). Extending the TAM for a t-commerce. Information \& Management, 42(7), 965-976.

Yuana, S. L., Sengers, F., Boon, W., \& Raven, R. (2019). Framing the sharing economy: A media analysis of ridesharing platforms in Indonesia and the Philippines. Journal of Cleaner Production, $212,1154-1165$.

Zhu, G., Li, H., \& Zhou, L. (2018). Enhancing the development of sharing economy to mitigate the carbon emission: A case study of online ride-hailing development in China. Natural Hazards, 91(2), 611-633.

Zhu, G., So, K. K. F., \& Hudson, S. (2017). Inside the sharing economy. International Journal of Contemporary Hospitality Management.

Publisher's note Springer Nature remains neutral with regard to jurisdictional claims in published maps and institutional affiliations. 